\title{
PATTERN OF SUDDEN AND UNEXPECTED NATURAL DEATHS- A REVIEW OF AUTOPSY CASES FROM 2012 to 2016
}

\author{
Balaram N. $A^{1}$, Aiswarya Sethumadhavan ${ }^{2}$
}

1 Professor and HOD, Department of Forensic Medicine, Government Medical College, Thrissur. 2Junior Resident, Department of Forensic Medicine, Government Medical College, Thrissur.

ABSTRACT
BACKGROUND
Sudden, unexplained and unexpected deaths are often a shock to the society. The cause of death being unknown, the body is subjected
to an autopsy to determine the same. It is important to identify the characteristics of the population involved and the pattern of
occurrence of such deaths to predict or prevent these terminal events. The aim of this study is to identify various causes, risk factors,
age and sex distribution associated with sudden and unexpected natural deaths (will be mentioned as SUNDs hereafter) in adults.

\section{MATERIALS AND METHODS}

The post-mortem registers, post-mortem detailed notes, KPF inquest forms and other relevant laboratory investigations of the cases that died due to SUNDs within the study period (2012-2016) were examined.

\section{RESULTS}

Of the total 7608 cases brought for autopsy at Government Medical College, Thrissur during the study period, 617 cases were due to SUNDs out of which $27.9 \%$ were in the age group between 51 to 60 years and $26.4 \%$ were between 41 and 50 years, predominantly being males (84.6\%). Cardiac causes $(74.1 \%)$ were more compared to noncardiac causes, which included respiratory (11.2\%), central nervous system (7.6\%), gastrointestinal system $(6.3 \%)$, genitourinary system $(0.5 \%)$, endocrine system $(0.2 \%)$ and multiorgan dysfunction causes $(0.2 \%)$. The important system responsible for SUNDs was CVS among all the other causes in adults over 40 years of age and was mainly due to coronary artery disease (62.9\%). The maximum occurrence of SUNDs being at home $(48.8 \%)$.

\section{CONCLUSION}

The productive age group of the society is at greater risk for SUNDs. Hence, seeking timely health advice, adequate patient awareness and modifications in diet and lifestyle can have a beneficiary effect.

\section{KEYWORDS}

Sudden Unexpected Natural Deaths, Coronary Artery Disease.

HOW TO CITE THIS ARTICLE: Balaram NA, Sethumadhavan A. Pattern of sudden and unexpected natural deaths- a review of autopsy cases from 2012 to 2016. J. Evolution Med. Dent. Sci. 2017;6(59):4343-4346, DOI: 10.14260/Jemds/2017/939

\section{BACKGROUND}

According to the World Health Organization (WHO), death is said to be sudden or unexpected when a person not known to have been suffering from any dangerous disease, injury or poisoning is found dead or dies within 24 hours after the onset of terminal illness. While death occurs on the spot due to violent trauma are homicidal, suicidal or accidental, it is an exception to death which has occurred all of a sudden.(1) However, sudden unexpected death is mainly defined as a rapid, unexpected, and natural death. This includes a healthy, non-fatally ill, or bedridden person who dies suddenly and unexpectedly (presumably from natural causes) as well as patients who die within 24 hours of admission into the hospital. Interestingly then, sudden death is not necessarily unexpected, and an unexpected death is not necessarily sudden.(2) It should be remembered that natural death means

Financial or Other, Competing Interest: None.

Submission 05-07-2017, Peer Review 17-07-2017,

Acceptance 20-07-2017, Published 24-07-2017.

Corresponding Author:

Dr. Aiswarya Sethumadhavan,

Junior Resident,

Department of Forensic Medicine,

Government Medical College, Thrissur.

E-mail: chinku90@gmail.com

DOI: $10.14260 /$ jemds $/ 2017 / 939$ that the death was caused entirely by the disease, and trauma or poison did not play any part in bringing it about.(3) Most of the cases of natural deaths belong to the category of sudden death in which death is unexpected and clinically unexplained or findings are obscure. Therefore, autopsy-based data regarding the causes of sudden death is important to determine the characteristics of the population involved and the pattern of occurrence of these terminal events.

Dr. Dinesh S Rao and Dr. Yadhukul(1) of the Department of Forensic Medicine, Sri Siddhartha Medical College, Agalkote, Tumkur in their study found out that unexplained deaths formed $8.67 \%$ of Medicolegal Autopsies and males were affected more. Cardiovascular pathology predominated all the other causes. Another study done by Olumuyiwa Eyitayo Pelemo, Donatus Sabageh, Akinwumi Oluwole Komolafe, Adedayo Olukemi Sabageh and William Olufemi Odesanmi(2) in Ile-Ife, Nigeria (OAUTHC) revealed similar results.

The objective of this study is to identify the pattern and trend of causes of sudden and unexpected natural deaths brought for autopsy at Government Medical College, Thrissur, and to study the sociodemographic factors related to the same.

\section{MATERIALS AND METHODS}

The study was a record-based descriptive study and the sample size was 7606 autopsy cases within the time period of 2012 to 2016. A protocol of the study was submitted to the 
Institutional Research Committee and Institutional Ethics Committee of Government Medical College, Thrissur and approved before data collection. The post-mortem registers, post-mortem detailed note, Kerala Police Force inquest forms, and relevant laboratory investigations of the cases that died due to sudden and unexpected death within the study period at Government Medical College Thrissur were examined. The data collected was tabulated based on the sociodemographic data, cause of death, systems involved, laboratory investigations and other details and analysis was done.

\section{RESULTS}

Of the total number of deaths during 2012 to 2016, SUNDs constituted $8.10 \%(\mathrm{n}=617)$. The maximum cases were in the age group of 51 to 60 years- 172 (27.9\%) followed by 41 to 50 years-163 (26.4\%) [Chart 1]. The mean age affected was $53+$ 13.5 , minimum being 18 years and maximum being 92 years.

Majority of the cases were males 522 (84.6\%), and the remaining were females 95 (15.4\%). [Chart 2].

The community which was affected the most was the Hindu community 489 (79.3\%), followed by Christian community 94 (15.2\%) and Muslim community 34 (5.5\%). [Chart 3].

The place of occurrence of SUNDs was mostly at home 301 (48.8\%), workplace 59 (9.6\%) and other places 257 (41.7\%) [Chart 4] which included hospital, roadside, temple premises, jail, hotel, meditation centre, train, etc. Similarly, the history of addictions of the deceased was not known 562 (91.9\%) in majority of the cases. Those known were alcoholics 55 (8.9\%). [Chart 5].

The pattern of SUNDs has been described as the systems affected, cause of death, comorbidities.

Cardiac causes 457 (74.1\%) predominated over noncardiac causes such as respiratory system 69 (11.2\%), central nervous system 47 (7.6\%), gastrointestinal system 39 (6.3\%), genitourinary system $3(0.5 \%)$, endocrine system 1 $(0.2 \%)$ and multiorgan dysfunction $1(0.2 \%)$. [Chart 6].

The main cause of death was coronary artery disease 388 (62.9\%). Other causes included pneumonia 40 (6.5\%), intracranial bleed $23(3.7 \%)$, coronary artery thrombosis 20 (3.2\%), cardiac tamponade 19 (3.1\%), pulmonary tuberculosis, subarachnoid bleed, alcoholic liver disease, peritonitis, lung abscess, oesophageal variceal bleed, rupture of aortic aneurysm, myocarditis, etc. [Table 1].

Majority of the comorbidities of the deceased were not known 576 (93.3\%). Others included myocardial infarction, diabetes mellitus, tuberculosis, atherosclerosis, chronic kidney disease, emphysema, end-stage fibrotic disease, epilepsy [Chart 7].

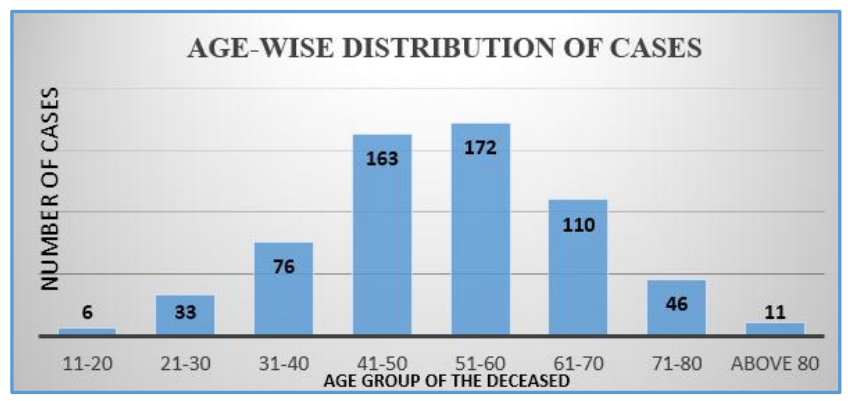

Chart 1. Distribution of Cases based on Age

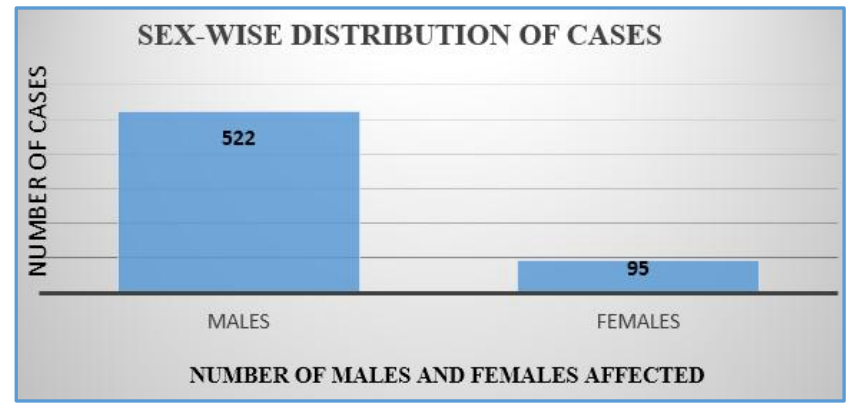

Chart 2. Distribution of Cases based on Sex

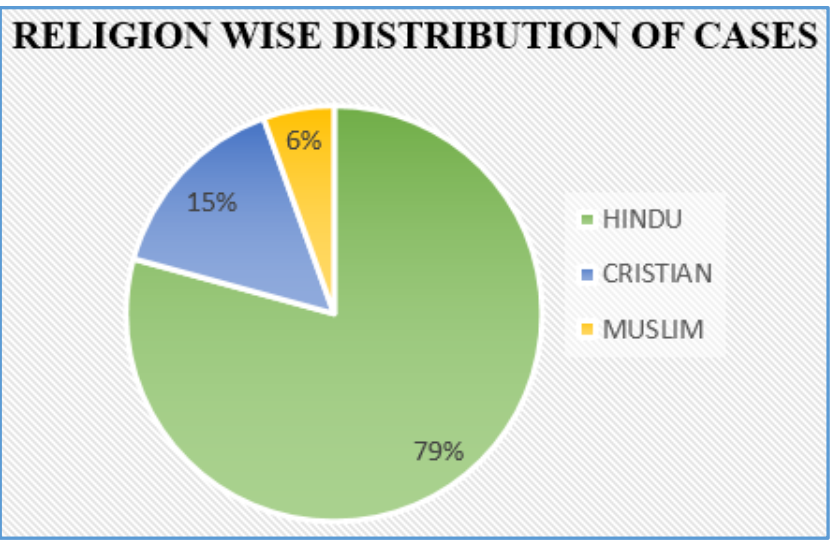

Chart 3. Distribution of Cases based on Religion

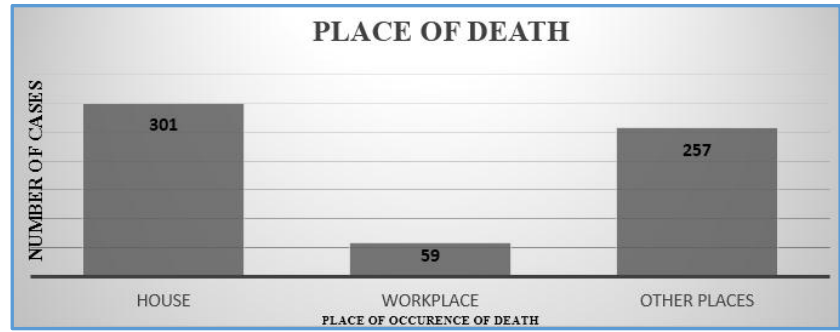

Chart 4. Distribution based on Place of Occurrence of Death

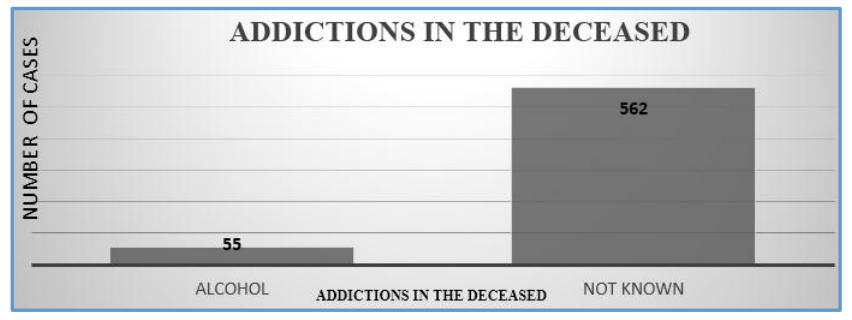

Chart 5. Addictions in the Deceased

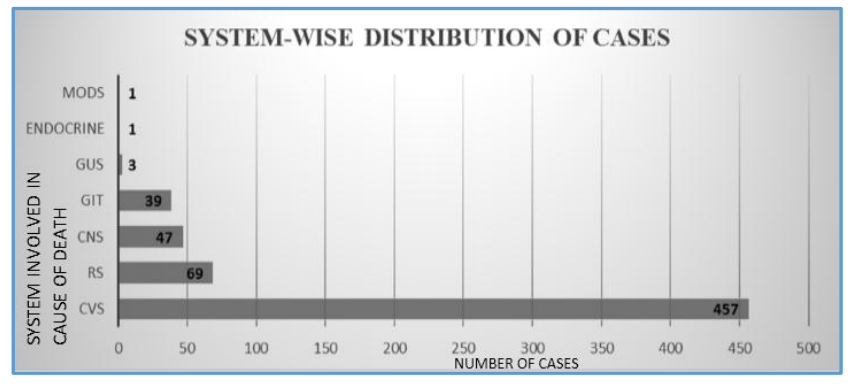

Chart 6. Distribution based on System Involved 


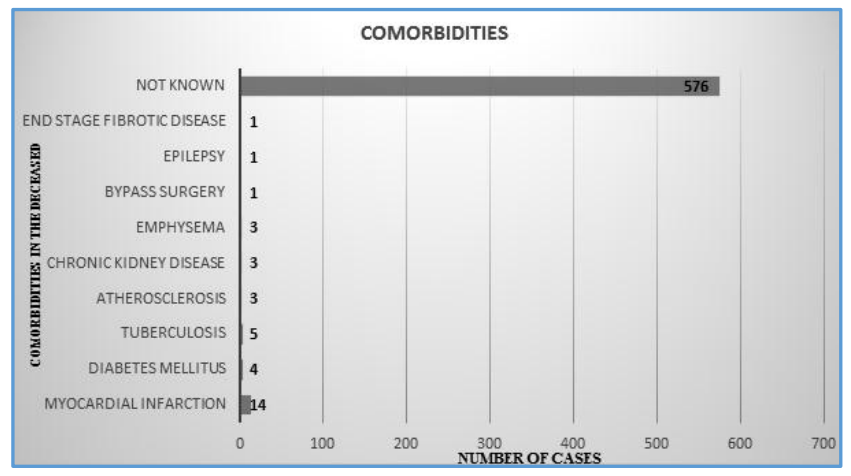

Chart 7. Comorbidities in the Deceased

\begin{tabular}{|c|c|c|}
\hline Cause of Death & No. of Cases & $\%$ \\
\hline Coronary artery disease & 388 & 62.9 \\
\hline Pneumonia & 40 & 6.5 \\
\hline Intracranial bleed & 23 & 3.7 \\
\hline Coronary artery thrombosis & 20 & 3.2 \\
\hline Cardiac tamponade & 19 & 3.1 \\
\hline Pulmonary tuberculosis & 15 & 2.4 \\
\hline Subarachnoid haemorrhage & 15 & 2.4 \\
\hline Alcoholic liver disease & 9 & 1.5 \\
\hline Peritonitis & 9 & 1.5 \\
\hline Oesophageal variceal bleed & 8 & 1.3 \\
\hline Rupture of aortic aneurysm & 7 & 1.1 \\
\hline Lung abscess & 6 & 1.0 \\
\hline Myocarditis & 6 & 1.0 \\
\hline Chronic liver disease & 5 & 0.8 \\
\hline Valvular heart disease & 5 & 0.8 \\
\hline Brainstem bleed & 3 & 0.5 \\
\hline Cardiomyopathy & 3 & 0.5 \\
\hline Chronic kidney disease & 3 & 0.5 \\
\hline Intestinal ischaemia & 3 & 0.5 \\
\hline Pancreatitis & 3 & 0.5 \\
\hline Subdural haemorrhage & 3 & 0.5 \\
\hline Cardiac failure & 2 & 0.3 \\
\hline Hepatorenal failure & 2 & 0.3 \\
\hline Miliary tuberculosis & 2 & 0.3 \\
\hline $\begin{array}{l}\text { Multi-organ dysfunction } \\
\text { syndrome }\end{array}$ & 2 & 0.3 \\
\hline Myocardial infarction & 2 & 0.3 \\
\hline Pulmonary embolism & 2 & 0.3 \\
\hline Acute bronchial asthma & 1 & 0.2 \\
\hline $\begin{array}{l}\text { Arrhythmogenic right } \\
\text { ventricular dysplasia }\end{array}$ & 1 & 0.2 \\
\hline Brain abscess & 1 & 0.2 \\
\hline Café coronary & 1 & 0.2 \\
\hline Cellulitis & 1 & 0.2 \\
\hline Cerebral infarction & 1 & 0.2 \\
\hline $\begin{array}{l}\text { Chronic obstructive pulmonary } \\
\text { disease }\end{array}$ & 1 & 0.2 \\
\hline Diarrheal disease & 1 & 0.2 \\
\hline Meningitis & 1 & 0.2 \\
\hline Phaeochromocytoma & 1 & 0.2 \\
\hline Pneumothorax & 1 & 0.2 \\
\hline Ventricular rupture & 1 & 0.2 \\
\hline \multicolumn{3}{|c|}{ Table 1. Distribution of Causes of Death } \\
\hline
\end{tabular}

\section{DISCUSSION}

The results of this study prove that SUNDs occur more in males in the age group of 41 to 60 years, mainly as a result of cardiac causes. Coronary artery disease had a greater predominance over all the other causes of death. These were similar to the results obtained by Dr Dinesh S Rao and Dr Yadhukul(1) of the Department of Forensic Medicine, Sri Siddhartha Medical College, Agalkote, Tumkur and the study done by Olumuyiwa Eyitayo Pelemo, Donatus Sabageh, Akinwumi Oluwole Komolafe, Adedayo Olukemi Sabageh and William Olufemi Odesanmi(2) on suburban Nigerian population.

Dr. Neerav Rana, Dr. Arvind Kumar Goyal, Dr. Chetan Kumar, Dr. V R Patil(3) in their study done at S.S.G. Medical College, Baroda found out that the incidence of sudden deaths was quite high in younger age group. Coronary narrowing was the major contributory cause and highest number of deaths was reported in males who were in their $4^{\text {th }}$ decade of life.

Jitta Udnoon, Thamrong Chirachariyavej and Vichan Peonim(4) conducted a retrospective autopsy study from 2003 to 2007 at Ramathibodi Hospital, Bangkok, Thailand and found out that sudden and unexpected natural deaths comprise up to $50-60 \%$ of all medicolegal deaths. The mean age was $55.3 \pm$ 0.98 years. The peak age group was the $46-60$ years accounting for $28.2 \%$ of cases, and the most common cause of death in all age groups was coronary atherosclerosis.

However, Sandip Mukhopadhyay, Sayak Sovan Dutta, Kaushik Ghosh, Anindya Kumar Goswami, Tanmay Sardar, Sanchita Das Kundu(5) conducted a retrospective study of sudden death cases in Medical College and Hospital, Kolkata and found that noncardiac causes (50.1\%) predominated slightly over cardiac causes (49.9\%). Noncardiac causes included central nervous system diseases (4.2\%), gastrointestinal diseases $(4.2 \%)$ and respiratory system diseases $(41.7 \%)$.

Sudden and unexpected natural death occurring in an apparently healthy and young individual is a loss to the society. Before deciding a death as sudden and unexpected natural death, one must rule out other causes such as poisoning, trauma, assault and prolonged illness.(6) In most of the cases, cause of death can be ruled out by a thorough and detailed autopsy.(7) However, some causes cannot be detected by autopsy such as arrhythmia, ventricular tachycardia, Brugada syndrome, long QT syndrome, channelopathies, seizure disorder, thyroid storm, hypokalaemia and the like(8). Thus a complete medicolegal autopsy with relevant histopathological examinations and chemical examinations should be done. Sometimes despite a normal report on autopsy, familial structural heart diseases are also possible. Keeping this in mind, molecular autopsy should be considered as a part of medicolegal investigation in sudden cardiac deaths without structural alterations.(9) Identification of genetic variations can help to enable genetic counselling and to undertake preventive measures in those relatives who are at risk. (10)

The productive age group of the society is at greater risk for SUNDs. Hence, seeking timely health advice, adequate patient awareness and modifications in diet and lifestyle can have a beneficiary effect.

\section{CONCLUSION}

Sudden and unexpected natural death occurring in an apparently healthy and young individual is a loss to the 
society. Before deciding a death as sudden and unexpected natural death, one must rule out other causes such as poisoning, trauma, assault and prolonged illness. In most of the cases, cause of death can be ruled out by a thorough and detailed autopsy. However, some causes cannot be detected by autopsy such as arrhythmia, ventricular tachycardia, Brugada syndrome, long QT syndrome, channelopathies, seizure disorder, thyroid storm, hypokalaemia and the like. Thus, a complete medicolegal autopsy with relevant histopathological examinations and chemical examinations should be done. Sometimes despite a normal report on autopsy, familial structural heart diseases are also possible. Keeping this in mind, molecular autopsy should be considered as a part of medicolegal investigation in sudden cardiac deaths without structural alterations. Identification of genetic variations can help to enable genetic counselling and to undertake preventive measures in those relatives who are at risk.

The productive age group of the society is at greater risk for SUNDs. Hence, seeking timely health advice, adequate patient awareness and modifications in diet and lifestyle can have a beneficiary effect.

\section{REFERENCES}

[1] Rao DS, Yadhukul. Sudden and unexpected natural deaths - a four year autopsy review. JPAFMAT 2008;8(2):20-4.

[2] Pelemo OE, Sabageh D, Komolef AO, et al. An autopsy review of sudden unexpected natural deaths in a suburban Nigerian population. Population Health Metrics 2014;12:26.
[3] Rana N, Goyal AK, Kumar C, et al. Autopsy study of sudden death in younger aged people of central Gujarat. IRMPS 2015;1(1):1-6.

[4] Udnoon J, Chirachariyavej T, Peonim V. Sudden unexpected deaths in different age groups at Ramathibodi Hospital, Bangkok, Thailand: a retrospective autopsy study during 2003-2007. Southeast Asian J Trop Med Public Health 2009;40(1):162-8.

[5] Sandip M, Dutta SS, Ghosh K, et al. A retrospective study of sudden death cases in medical college and hospital, Kolkata. Journal of Dental and Medical Sciences 2015;14(1): Ver. 6, 9-18.

[6] Anderson RE, Hill RB, Broudy DW, et al. A populationbased autopsy study of sudden unexpected deaths from natural causes among persons 5 to 39 years old during a 12-year period. Human Pathology 1994;25(12):133240.

[7] Bhagora LR, Parmar AP, Parmar DC, et al. Sudden death - an autopsy based study. Int J Res Med 2015;4(4): 154-7.

[8] Reddy KSN. The essentials of forensic medicine and toxicology. 33 $3^{\text {th }}$ edn. Hyderabad: Jaypee Brothers Medical Publishers 2014:150-1.

[9] Karmakar RN. JB Mukherjee's Forensic medicine and toxicology. $4^{\text {th }}$ edn. Kolkata: Academic Publishers 2011:225-6.

[10] Di Maoi VJ, Di Maoi DJ. Natural Death as viewed by the Medical Examiner: A review of 1000 consecutive autopsies of individuals dying of natural disease. J Forensic Sci 1991;36(1):17-24. 